\title{
Active Power Control of Grid tied PV system using Fuzzy Controller
}

\author{
Y Lakshmi $^{1}$ | P Ankineedu Prasad ${ }^{2}$ \\ ${ }_{1}^{1}$ PG Student, Dept of EEE, Vikas Group of Institutions, Vijayawada, India \\ ${ }^{2}$ Associate Professor, Dept of EEE, Vikas Group of Institutions, Vijayawada, India
}

\section{To Cite this Article}

Y Lakshmi and P Ankineedu Prasad, "Active Power Control of Grid tied PV system using Fuzzy Controller", International Journal for Modern Trends in Science and Technology, 6(8): 1-4, 2020.

\section{Article Info}

Received on 22-May-2020, Revised on 22-June-2020, Accepted on 25-July-2020, Published on 27-July-2020.

\section{ABSTRACT}

Historically, electric power system operators have seen photovoltaic (PV) power systems as potential sources of problems due to intermittency and lack of controllability. However, the flexibility of power electronic inverters allows $P V$ to provide grid-friendly features including volt-VAR control, ramp-rate control, high-frequency power curtailment, and event ride-through. Commercially available smart PV inverters can further provide frequency down-regulation by curtailing power, but they are unable to provide true frequency regulation through active power control (APC) because they are unable to increase power on command. This paper proposes a coordinated DC-link voltage control and deloading control for two-stage PV system to offer frequency support in an islanded microgrid without energy storage system (ESS). This paper proposes a predictive fuzzy logic based PV inverter control method for very fast and accurate control of active power

\section{INTRODUCTION}

Power supply and power quality have been critical issues in power system recently. The grid-connected photovoltaic (PV) generator has nowadays become more popular because of its reliable performance and its ability to generate power from clean energy resources. The dc output voltage of PV arrays is connected to a dc/dc boost converter using a maximum power point tracking (MPPT) controller to maximize their produced energy. Then, that converter is linked to a dc/ac voltage source converter (VSC) to let the PV system push electric power to the ac utility. The local load of the PV system can specially be a non- linear load, such as computers, compact fluorescent lamps, and many other home appliances, that requires distorted currents. Development of a means to compensate the distribution system harmonics is equally urgent. In this case, PV generators should provide the utility with distorted compensation capability, which makes currents injected/absorbed by the utility to be sinusoidal. Therefore, the harmonic compensation function can be realized through flexible control of $\mathrm{dc} / \mathrm{ac}$ VSC. Instantaneous power theory has successfully completed active power filter (APF) designing with good performance. However, the PV-APF combination has just been gradually developed for several years. This combination is capable of simultaneously compensating power factor, current imbalance, and current harmonics, and also of injecting the energy generated by PV with low total harmonic distortion (THD). Even when there is no energy available from PV, the combination can still operate to enhance the power quality of the utility. To the best of our knowledge, this idea was initiated in 1996 by Kim et al.. In this study, the PV system needs energy storage 
elements, which negatively increase the entire cost. Besides, the mathematical demonstration was not sufficiently provided. After that, the control techniques have been improved in some later efforts to develop PV inverters with real power injection and APF features. However, their research did not show consistent results obtained by their proposed theories, and they are applicable for a single-phase PV only. The most recent completely released paper in 2013 uses current references as the main functions of the $\mathrm{dc} / \mathrm{ac}$ controller, which coincides with the basic ideas of this paper. By another manner in this paper, the proposed PV-APF controller utilizing power references shows some significant improvements in theory and a simple control topology. The PV-APF system helps the utility supply a unity power factor and pure sinusoidal currents to the local nonlinear loads by generating the oscillating and imaginary components. When there is an excess power, that PV unit will only inject average power to the utility. As a result, this system can be considered as a distributed APF, which is a better solution than adopting passive filters or centralized APFs.

\section{PROPOSED SYSTEM}

The configuration of the three-phase grid-connected inverter for the grid-connected and islanding operations is shown in Fig. 1. The power circuit contains a microsource such as photovoltaic panels and fuel cells represented by the dc source, a three-phase pulse width modulation (PWM) inverter, a three phase sensitive load connected to the output of the LCL filter, a static transfer switch (STS) for grid-on or grid-off control, and an LCL filter with a damping resistor. An LCL filter is used instead of an L filter, as it can provide higher high-frequency harmonic attenuation with the same inductance value. However, a system with an LCL filter has an inherent high-resonant peak at the resonant frequency of the LCL filter, which would make the current control system unstable. To avoid this stability problem, various active damping approaches for PI-based current control of a grid-connected inverter with an LCL filter are proposed by using additional feedback or by adjusting the ratio of the control frequency and resonance frequency of the LCL filter. Several active damping strategies for LCL filters are suggested. In this paper, a passive damping method with a damping resistor is used as shown in Fig. 1. The control system consists of a grid current control for grid-connected operation, and a load voltage control for islanding operation. The outputs of the $\mathrm{d}-\mathrm{q}$ grid current controllers are connected to those of the $\mathrm{d}-\mathrm{q}$ load voltage controllers, in order to prevent a sudden change of the outputs of both controllers at the mode transfer instant. In [2], the outputs of both the current and voltage controllers are connected together at a single-phase grid-connected inverter. However, because the outputs of both controllers are ac voltages, the phase between the two outputs should be matched.

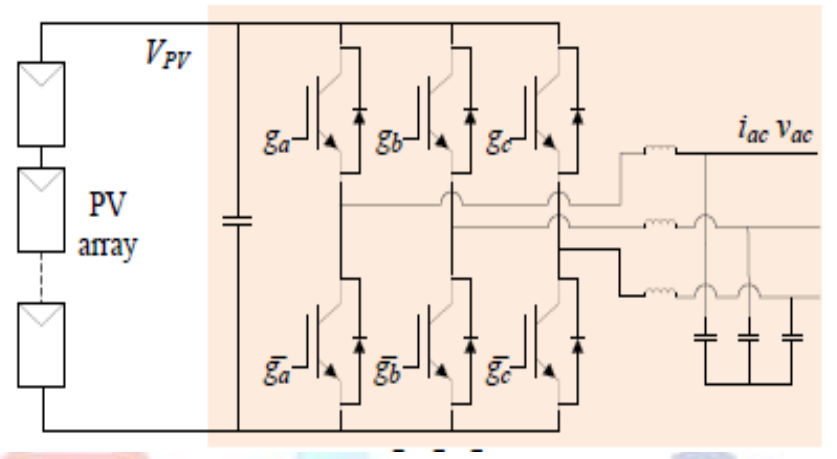

Figure 1: Proposed PV System using APC

The $V_{P V}$ voltage controller regulates the PV voltage by sending the $\mathrm{d}$-axis current command, $i d$, as in [4]. The inverter's output current is controlled in the DC-AC controller block using sinusoidal pulse-width modulation (PWM) with independent proportional-integral (PI) control on the d-axis and q-axis currents in the rotating synchronous (dq) reference frame, as in [4]. Reactive power output can be controlled separately by regulating the q-axis current command iq in the voltage regulation block, but that is not the focus here.

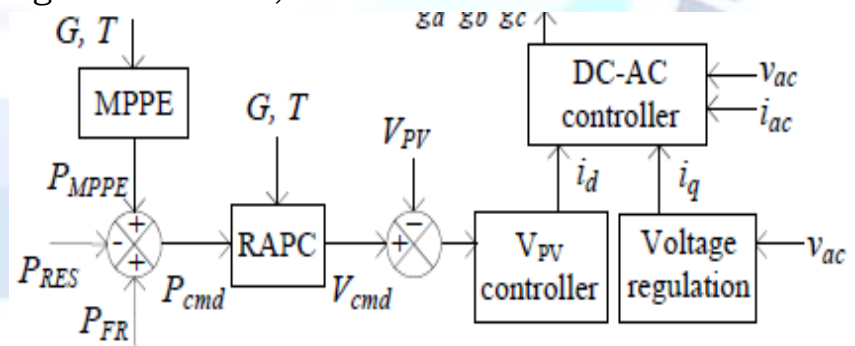

Frequency regulation

Figure 2: Control Structure for PV Inverter

\section{FUZZY LOGIC CONTROLLER}

In the previous section, control strategy based on PI controller is discussed. But in case of PI controller, it has high settling time and has large steady state error. In order to rectify this problem, this paper proposes the application of a fuzzy logic controller (FLC) shown in figure 7. Generally, the FLC is one of the most important software based technique in adaptive methods [7]. 
As compared with previous controllers, the FLC has low settling time, low steady state errors. The operation of fuzzy controller can be explained in four steps.

1. Fuzzification

2. Membership function

3. Rule-base formation

4. Defuzzification.

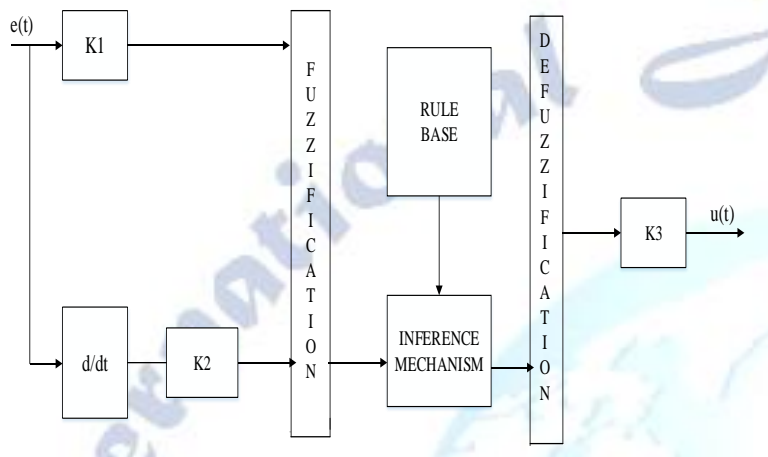

Figure 3: Basic structure of fuzzy logic controller

In this paper, the membership function is considered as a type in triangular membership function and method for defuzzification is considered as centroid. The error which is obtained from the comparison of reference and actual values is given to fuzzy inference engine. The input variables such as error and error rate are expressed in terms of fuzzy set with the linguistic terms VN, N, Z, P, and Pin this type of mamdani fuzzy inference system the linguistic terms are expressed using triangular membership functions. In this paper, single input and single output fuzzy inference system is considered. The number of linguistic variables for input and output is assumed as 3.The number of rules are formed as 9.The input for the fuzzy system is represented as error of PI controller. The fuzzy rules are obtained with if-then statements. The given fuzzy inference system is a combination of single input and single output. This input is related with the logical operator AND/OR operators. AND logic gives the output as minimum value of the input and OR logic produces the output as maximum value of input.

\section{SIMULATION DIAGRAM \& RESULT}

For demonstration purposes, the MPPE method was implemented in a three-phase, single-stage prototype inverter using a simple three-phase bridge power stage and an L-C output filter in MATLAB/Simulink Environment, as shown in Figure 4.

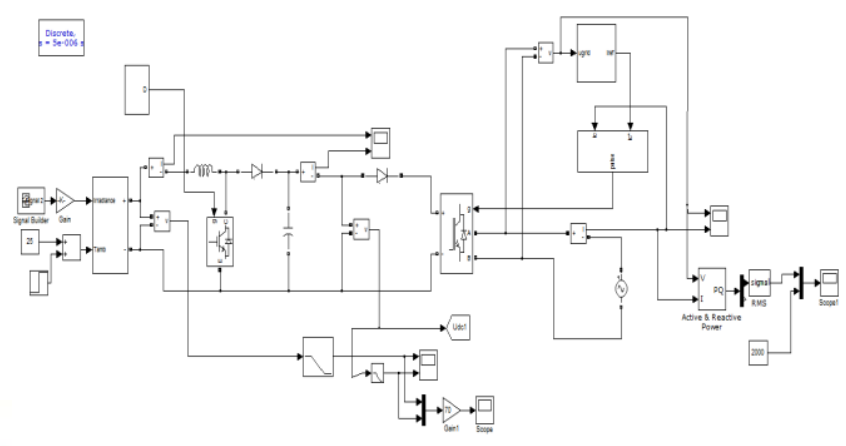

Figure 4: Simulation Diagram for PV-Grid System Case 1: Implementation of Proposed system with Conventional Controller.

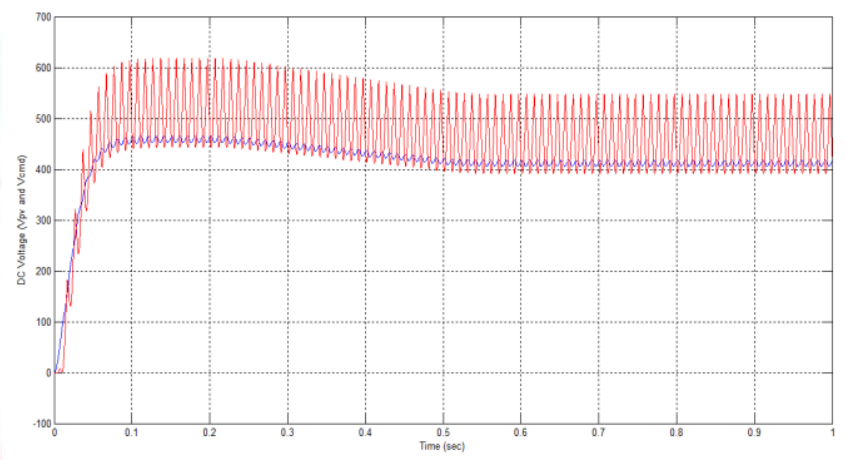

Figure 5: Simulation Result for DC Voltage for PV and CMD

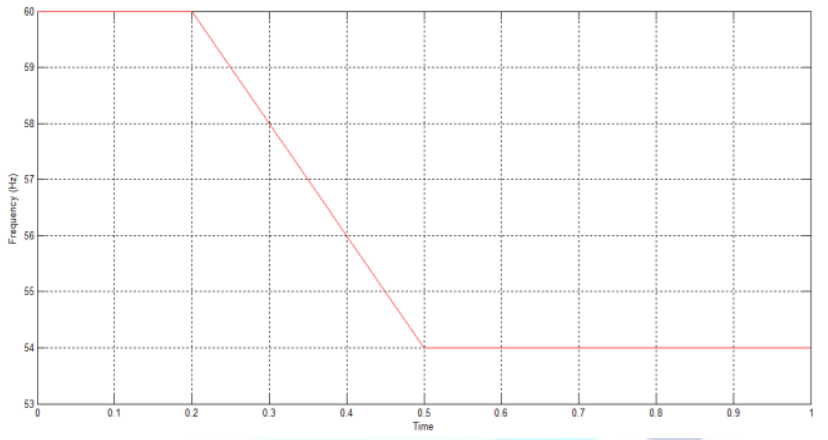

Figure 6: Simulation Result for Frequency

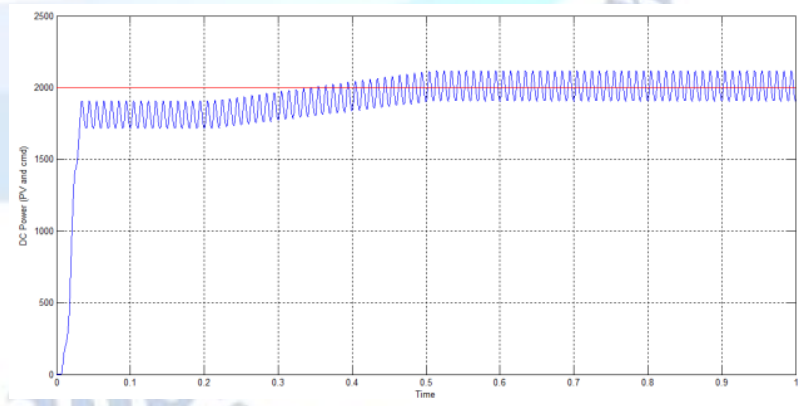

Figure 7: Simulation Result for DC Powers of PV and $\mathrm{cmd}$

The frequency regulation block in Fig. 5 was programmed with a $5 \%$ droop slope. This means that a frequency change equal to $5 \%$ of the nominal frequency, or $3 \mathrm{~Hz}$, will result in a change of $100 \%$ of the inverter's nominal power, so $P F R=P O \cdot(f-$ $f 0) /(f 0 \cdot 0.05)$, where $P 0$ is the rated inverter power, $f$ is the measured grid frequency from the PLL, and 
$f 0=60 \mathrm{~Hz}$. A $5 \%$ droop slope is a common value used in synchronous machines, though machine droop response is orders of magnitude slower than the inverter responses shown below.

Case 2: Implementation of Proposed system with Fuzzy Logic Controller.

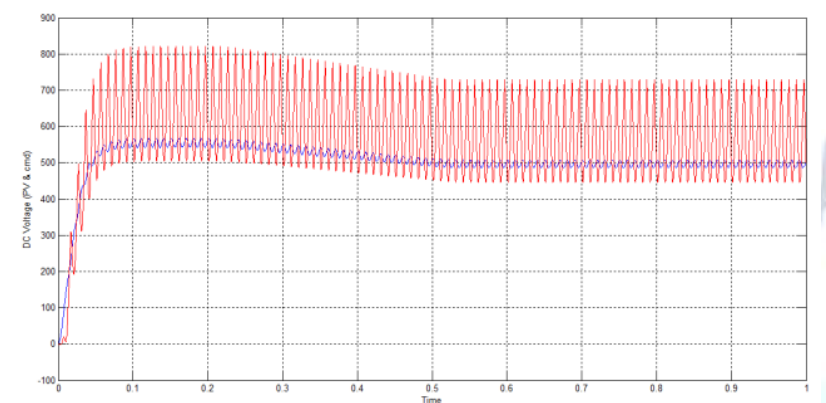

Figure 8: Simulation Result for DC Voltage for PV and CMD

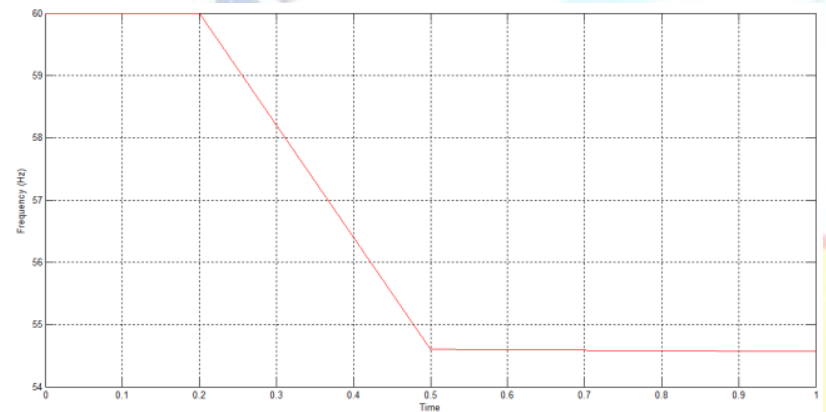

Figure 9: Simulation Result for Frequency

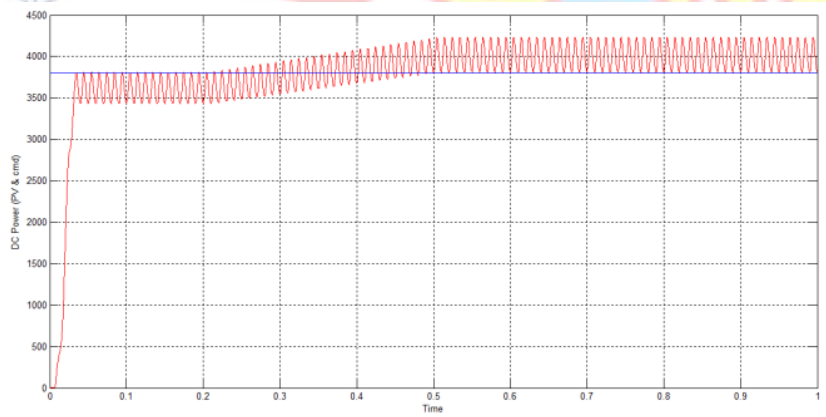

Figure 10: Simulation Result for DC Powers of PV and $\mathrm{cmd}$

\section{v. Conclusion}

The rapid active power control method introduced here has been experimentally shown to provide very fast and accurate response to a demanding range of grid frequency events and tested in Matlab/Simulink using conventional and Fuzzy logic conrollerss. The experimental validation used two real PV arrays to demonstrate that the method is robust to realistic changes in weather conditions. Used in conjunction with a PV maximum power point estimation method experimentally validated here, the RAPC method enables a suite of fast-responding PV inverter active power control methods, including but not limited to the fast power-frequency droop response demonstrated here. There has been little incentive in the past for grid-interactive PV inverters to have particularly high-bandwidth PLLs or DC voltage controllers. However, for emerging applications such as rapid active power control, the experimental results with fuzzy logic control presented here suggest it may be beneficial to design faster low-level controls, allowing still faster response to frequency events or other grid disturbances.

\section{REFERENCES}

[1] P. Kundur, Power system stability and control. McGraw-Hill New York, 1994.

[2] "FERC Order No. 755: Frequency Regulation Compensation in the Organized Wholesale Power Markets." U.S. Federal Energy Regulatory Commission (FERC), Oct-2011.

[3] "FERC Order No. 819: Third-Party Provision of Primary Frequency Response Service.” Federal Energy Regulatory Commission, 20-Nov-2015.

[4] 'Hawaiian Electric Companies' PSIP Update Report: Book 2 of 2," The Hawaiian Electric Companies, in PUC Docket No. 2014-0183, Apr. 2016.

[5] V. Gevorgian and B. O'Neill, "Advanced Grid-Friendly Controls Demonstration Project for Utility-Scale PV Power Plants," NREL, NREL/TP-5D00-65368, Jan. 2016.

[6] P. M. S. Carvalho, P. F. Correia, and L. A. F. M. Ferreira, "Distributed Reactive Power Generation Control for Voltage Rise Mitigation in Distribution Networks," IEEE Trans. Power Syst., vol. 23, no. 2, pp. 766-772, May 2008.

[7] "IEEE Standard 1547a - Standard for Interconnecting Distributed Resources with Electric Power Systems Amendment 1," IEEE, 2014.

[8] "Minimum Technical Requirements for Photovoltaic Generation (PV) Projects," Puerto Rico Electric Power Authority, Nov. 2011.

[9] B. I. Crăciun, T. Kerekes, D. Séra, and R. Teodorescu, "Frequency Support Functions in Large PV Power Plants With Active Power Reserves," IEEE J. Emerg. Sel. Top. Power Electron., vol. 2, no. 4, pp. 849-858, Dec. 2014.

[10] "Electricity Storage Technology Brief," International Energy Agency Energy Technology Systems Analysis Programme (IEA-ETSAP) and International Renewable Energy Agency (IRENA), Apr. 2012. 